\title{
2'-Fucosyllactose promotes Bifidobacterium bifidum DNG6 adhesion to Caco-2 cells
}

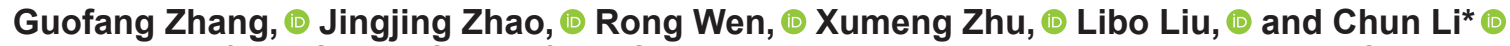 \\ Key Laboratory of Dairy Science, College of Food Science, Northeast Agricultural University, Harbin, 150030, China
}

\begin{abstract}
Adhesion to the intestinal mucosa is the prerequisite for bifidobacteria to colonize and exert biological functions, whereas the choice of carbon source affects the ability of bifidobacteria to adhere to and interact with intestinal epithelial cells. However, knowledge about the relationship between human milk oligosaccharide consumption by bifidobacteria and its adhesion is still limited. In this study, we aim to investigate the effect of 2'-fucosyllactose (2'-FL) as the carbon source on the growth and adhesion properties of Bifidobacterium bifidum DNG6, and make comparisons with galactooligosaccharides and glucose. We found that the growth and adhesion properties of $B$. bifidum DNG6 grown in different carbon sources were varied. The 2 '-FL as a carbon source improves the adhesion ability of B. bifidum DNG6. The expression of adhesion-associated genes was significantly higher in $B$. bifidum DNG6 grown in 2'-FL after incubation with Caco-2 cells compared with that in galactooligosaccharides and glucose. Our results indicated that $2^{\prime}$-FL may promote $B$. bifidum DNG6 adhesion to Caco-2 cells through high expression of genes encoding adhesion proteins. The findings of this study contribute to a better understanding of the involvement of human milk oligosaccharides in the adhesion of bifidobacteria and further support the potential application of 2 -FL as a prebiotic in infant nutritional supplements.
\end{abstract}

Key words: Bifidobacterium bifidum, 2'-fucosyllactose, adhesion, surface proteins

\section{INTRODUCTION}

Bifidobacteria are heterofermentative gram-positive bacteria and are particularly enriched in the intestine of breastfed infants due to the large amounts of human milk oligosaccharides (HMO) in breast milk that

Received April 22, 2020

Accepted June 29, 2020.

*Corresponding author: spxylch@126.com support the growth of Bifidobacterium (Turroni et al., 2012; Ruiz-Moyano et al., 2013; Matsuki et al., 2016; Yassour et al., 2016). As a probiotic, bifidobacteria contribute to the health of the host, including modulating the balance of intestinal microbiota, promoting the development of the immune system, maintaining the integrity of the mucosal barrier, and resisting the colonization of pathogens (Gareau et al., 2010; Sivan et al., 2015).

To achieve these beneficial effects, adhesion to the intestinal mucosa is the prerequisite for bifidobacteria colonization and persistence in the gastrointestinal tract (Riedel et al., 2006; Ventura et al., 2012). Cell surface proteins play an important role in the bifidobacteria to adhere to and interact with intestinal epithelial cells (Westermann et al., 2016), including pili or fimbriae and some secondary proteins such as elongation factor $\mathrm{Tu}$ (EF-Tu), chaperone protein DnaK and GroEL, bile salt hydrolase, glutamine synthetase, and so on (Candela et al., 2007; Duranti et al., 2014; Wei et al., 2016; Zhu et al., 2016). Many researchers have demonstrated that in addition to the primary catalytic effect, some enzymes of the bifid shunt are also involved in bacterial adhesion, including transaldolase (Tal), enolase (Eno), and glyceraldehyde phosphate dehydrogenase (Candela et al., 2009; Gilad et al., 2011; Liu et al., 2011; González-Rodríguez et al., 2012).

Human milk oligosaccharide, the second-largest carbohydrate component of human breast milk, plays a critical role in the establishment and composition of the initial intestinal microbiota, dominated by Bifidobacterium species (Thomson et al., 2018). 2'-Fucosyllactose (2'-FL, Fuc $\alpha 1-2 \mathrm{Gal} \beta 1-4 \mathrm{Glc})$, a major oligosaccharide in human milk, which is formed from lactose by fucosylation in $\alpha-1,4$-glycosidic linkage at the terminal galactose (Ninonuevo et al., 2006; Bode and JantscherKrenn, 2012). The 2'-FL attributes many potential health benefits for infants, such as immune system modulation, host-microbe interactions, brain development, and cognitive functions (Vázquez et al., 2015; He et al., 2016; Matsuki et al., 2016). Galactooligosaccharides (GOS) and fructooligosaccharides are usually added to infant formula in a certain proportion 
to partly replace the function of HMO (Vandenplas et al., 2015), but they are much simpler in structure than HMO (Roberfroid and Slavin, 2000; Torres et al., 2010). Galactooligosaccharides and fructooligosaccharides are linear polymers of residues of galactose or fructose with terminal glucose, whereas HMO are characterized by a lactose core at the reducing end, and typically modified by a fucose or sialic acid residue at the nonreducing end (Ninonuevo et al., 2006; Bode and Jantscher-Krenn, 2012).

One study showed that HMO-grown Bifidobacterium longum ssp. infantis had significantly higher adhesion ability to Caco-2 cells compared with that in glucose and lactose (Wickramasinghe et al., 2015). The HMO utilization by $B$. longum ssp. infantis triggers the expression of surface adhesion proteins that interact with intestinal cells, and alters gene expression in Caco-2 cells in accordance with a protective regulatory mechanism in the host gut (Chichlowski et al., 2012). Kavanaugh et al. (2013) confirmed that B. longum ssp. infantis growth in $6{ }^{\prime}$-sialyllactose also increased the adhesion ability to intestinal epithelial cells. In Bifidobacterium adolescentis, cell surface pili may play a role in its adhesion and their pilus gene clusters were differentially expressed depending on the carbon sources in the growth medium (Duranti et al., 2014).

It is evident that the types of carbon sources, especially the oligosaccharides with a specific structure, are crucial for selectively promoting bifidobacteria colonization while affecting the interaction of bifidobacteria with intestinal epithelial cells (Turroni et al., 2010; Nishiyama et al., 2017). However, the literature on the relationship between 2'-FL consumption by bifidobacteria and its adhesion is still limited.

In this study, we aim to investigate the effect of $2^{\prime}$ FL as a carbon source on the growth and adhesion properties of B. bifidum DNG6, and make comparisons with GOS and glucose. The results of this study may help us better understand the adhesion mechanism of bifidobacteria from the perspective of carbon source utilization. Furthermore, our data provide new insights into the design of symbiotic supplements and also support the potential application of 2 '-FL as a prebiotic for infant nutritional supplements.

\section{MATERIALS AND METHODS}

\section{Bacterial Strains and Culture Conditions}

Bifidobacterium bifidum DNG6 (isolated from adult feces) and Bifidobacterium animalis ssp. lactis BB12 were obtained from the Key Laboratory of Dairy Science (Harbin, China). The strains were cultured in modified de Man, Rogosa, and Sharpe medium (BD
Difco, Detroit, MI) supplemented with $0.05 \%$ (wt/vol) L-cysteine at $37^{\circ} \mathrm{C}$ in an anaerobic incubator (Thermo Fisher Scientific, Waltham, MA).

\section{Growth Characteristics of B. bifidum DNG6}

Bifidobacterium bifidum DNG6 was inoculated (2\%, $\mathrm{vol} / \mathrm{vol}$ ) into the tubes containing $10 \mathrm{~mL}$ of medium with the $2 \%$ (wt/vol) filter-sterilized glucose, $2 \%$ GOS, or $2 \% 2^{\prime}-\mathrm{FL}$ as the sole carbon source, then incubated for $36 \mathrm{~h}$ at $37^{\circ} \mathrm{C}$ in an anaerobic incubator (Thermo Fisher Scientific). The absorbance of the culture was monitored at $600 \mathrm{~nm}$ in a spectrophotometer DU 640 (Beckman, Fullerton, CA) every 2 h, and growth curves were prepared. Glucose and GOS were purchased from Sigma-Aldrich (Taufkirchen, Germany), and 2'-FL was purchased from Sharing Technologies (Shanghai, China).

\section{Autoaggregation Assay}

The autoaggregation assay was performed according to previous research with some modifications (GonzálezRodríguez et al., 2012). Briefly, bacterial cells were harvested by centrifugation at $6,000 \times g$ for $10 \mathrm{~min}$ at $4^{\circ} \mathrm{C}$, washed twice, and resuspended in PBS $(0.2 \mathrm{M}$ $\mathrm{Na}_{2} \mathrm{HPO}_{4} \cdot 12 \mathrm{H}_{2} \mathrm{O}$ and $0.2 M \mathrm{NaH}_{2} \mathrm{PO}_{4} \cdot 2 \mathrm{H}_{2} \mathrm{O}, \mathrm{pH}$ 7.4). Then, the $\mathrm{A}_{600}$ value of the suspension was adjusted to $0.8 \pm 0.02\left(\mathrm{~A}_{0}\right)$. Bacterial suspensions $(10 \mathrm{~mL}, 1 \times$ $10^{8} \mathrm{cfu} / \mathrm{mL}$ ) were mixed and incubated for $5 \mathrm{~h}$ at room temperature, and then the absorbance was measured at $600 \mathrm{~nm}\left(\mathrm{~A}_{1}\right)$. The autoaggregation rate was calculated as using the following formula: autoaggregation $\%=(1$ $\left.-\mathrm{A}_{1} / \mathrm{A}_{0}\right) \times 100$, where $\mathrm{A}_{1}$ and $\mathrm{A}_{0}$ represent absorbance values at 5 and $0 \mathrm{~h}$, respectively.

\section{Cell Surface Hydrophobicity Assay}

Cell surface hydrophobicity assay was performed according to the method of bacterial adhesion to hydrocarbons as previously described (Pan et al., 2006) with some modifications. Bacterial cells were harvested by centrifugation at $6,000 \times g$ for $10 \mathrm{~min}$ at $4^{\circ} \mathrm{C}$, washed twice in PBS, and resuspended in $0.1 \mathrm{M} \mathrm{KNO}_{3}$. Then, the suspension was adjusted to an optical density value of $0.8 \pm 0.02$ at $600 \mathrm{~nm}\left(\mathrm{~A}_{0}\right)$. Bacterial suspensions $(15$ $\mathrm{mL}$ ) were mixed with xylene $(5 \mathrm{~mL})$ and incubated for $10 \mathrm{~min}$ at room temperature to form a 2-phase system. The system was vortexed for $2 \mathrm{~min}$ and then allowed to separate (aqueous phase and organic phase) by incubation for $20 \mathrm{~min}$. The aqueous phase was carefully removed and the $A_{600}$ was measured $\left(A_{1}\right)$. The percentage of cell surface was calculated using the following formula: hydrophobicity $\%=\left(1-A_{1} / A_{0}\right) \times 100$, where 
$\mathrm{A}_{0}$ and $\mathrm{A}_{1}$ were absorbance values before and after extraction with xylene, respectively.

\section{Caco-2 Cell Culture}

Enterocyte-like Caco-2 cells were obtained from the American Type Culture Collection (HTB-37, Manassas, VA). The Caco-2 cells were grown using in Dulbecco's modified Eagle medium (Hyclone, Logan, UT) supplemented with $20 \%$ (vol/vol) heat-inactivated fetal bovine serum, $1 \%$ antibiotics $(100 \mathrm{IU} / \mathrm{mL}$ penicillin and $100 \mu \mathrm{g} / \mathrm{mL}$ streptomycin), $1 \%$ NEAA, and $2 \mathrm{mM}$ L-glutamine (all from Hyclone). The cells were cultured in $25-\mathrm{cm}^{2}$ flasks at $37^{\circ} \mathrm{C}$ in a $5 \% \mathrm{CO}_{2}$ water-jacketed incubator (Thermo Fisher Scientific, Waltham, MA) and the culture medium was replaced every other day. For adhesion assay, Caco-2 cells were seeded in 6-well tissue culture plates (Corning, NY) at $1 \times 10^{5}$ cells per well and maintained for 2 wk after confluence.

\section{Adhesion Assay}

Adhesion to Caco-2 cells was assayed as reported previously with slight modifications (Bianchi et al., 2004). Bacterial cells were collected by centrifugation $\left(6,000 \times g\right.$ for $10 \mathrm{~min}$ at $\left.4^{\circ} \mathrm{C}\right)$ and washed twice with PBS. Then, $1 \mathrm{mmol} / \mathrm{L}$ CFDA-SE solution $[5.0 \mathrm{mg}$ 5(6)-carboxyfluorescein diacetate dissolved in $8.969 \mathrm{~mL}$ of dimethylsulfoxide; Beyotime, Shanghai, China] was added to the bacterial suspension at a final concentration of $20 \mu \mathrm{mol} / \mathrm{L}$. Then the suspension was incubated in the dark at $37^{\circ} \mathrm{C}$ for $20 \mathrm{~min}$, and centrifuged and washed again to remove excess dye. Two milliliters of CFDA-labeled bacteria $\left(1 \times 10^{8} \mathrm{cfu} / \mathrm{mL}\right)$ was added to the confluent monolayer of Caco-2 cells followed by incubation at $37^{\circ} \mathrm{C}$ for $2 \mathrm{~h}$. After incubation, unbound bacteria were removed by washing 3 times with PBS and the adhered bacteria cells were released by adding $250 \mu \mathrm{L}$ of $0.25 \%$ trypsin-EDTA $(0.25 \%$ Trypsin and $0.02 \%$ EDTA, Hyclone) for $2 \mathrm{~min}$ at $37^{\circ} \mathrm{C}$. Then the fluorescence intensity was measured using a fluorescence spectrophotometer (F-4500, Hitachi, Tokyo, Japan) in the following conditions: excitation wavelength of $492 \mathrm{~nm}$, emission wavelength of $517 \mathrm{~nm}$, and slit width of $2.5 \mathrm{~nm}$. The percentage of adhesion rate was represented by the ratio of the fluorescence intensity of bacteria adhesion to Caco-2 cells to the original fluorescence intensity of bacteria.

\section{Treatments During Adhesion Assay}

Bifidobacterium bifidum DNG6 was grown overnight anaerobically at $37^{\circ} \mathrm{C}$ in $300 \mathrm{~mL}$ of modified de Man,
Rogosa, and Sharpe medium with $2 \%$ (wt/vol) glucose, and then bacterial cells were harvested by centrifugation $\left(6,000 \times g\right.$ for $10 \mathrm{~min}$ at $\left.4^{\circ} \mathrm{C}\right)$ and washed twice with PBS. Then, $15 \mathrm{~mL}$ of lithium chloride ( $\mathrm{LiCl}, 5 \mathrm{~mol} / \mathrm{L})$, sodium periodate $\left(\mathrm{NaIO}_{4}, 0.05 \mathrm{~mol} / \mathrm{L}\right)$, proteinase $\mathrm{K}$ $(0.5 \mathrm{mg} / \mathrm{mL})$, or phenol $(\mathrm{PhOH}, 0.8 \mathrm{~mol} / \mathrm{L})$ was added to the above bacterial precipitate then incubated at $37^{\circ} \mathrm{C}$ for $30 \mathrm{~min}$, respectively. After incubation, the bacterial cells were collected by centrifugation and used for adhesion assays. The bacterial adhesion rate was tested after different treatments as mentioned above, and the untreated bacteria were used as a control. The relative change of adhesion was calculated as a percentage (González-Rodríguez et al., 2012).

\section{Transmission Electron Microscopy Observation}

The cell surface characteristics of bacteria were observed as described by Zhu et al. (2016). Bifidobacterium bifidum DNG6 was cultured anaerobically overnight at $37^{\circ} \mathrm{C}$ in an Erlenmeyer flask containing $200 \mathrm{~mL}$ of medium with $2 \%$ (wt/vol) glucose, and was harvested by centrifugation $\left(6,000 \times g\right.$ for $10 \mathrm{~min}$ at $\left.4^{\circ} \mathrm{C}\right)$ and washed twice with PBS. Subsequently, $10 \mathrm{~mL}$ of $\mathrm{LiCl}$ $(5 \mathrm{~mol} / \mathrm{L})$ was added to the above bacterial cells, then incubated at $37^{\circ} \mathrm{C}$ for $30 \mathrm{~min}$. After incubation, the bacterial precipitate was collected by centrifugation, and then fixed with $3 \%$ glutaraldehyde for $2 \mathrm{~h}$ at room temperature. After being washed 5 times with PBS, the samples were dipped into $1 \%$ phosphotungstic acid for $1 \mathrm{~h}$, dehydrated by $30,50,70,90$, and $100 \%$ graded ethanol for $5 \mathrm{~min}$ each, and dried in a drying chamber. The specimens were observed under a transmission electron microscope (HT7700, Hitachi, Tokyo, Japan), and the untreated bacteria were used as a control.

\section{Expression of Genes in B. bifidum DNG6 in Response to Incubation with Caco-2 Cells}

The expression levels of target genes in B. bifidum DNG6 in the presence or absence of Caco-2 cells were analyzed by reverse transcription quantitative real-time PCR (RT-qPCR). The sequences of the primers are listed in Table 1. Bacterial cells were incubated with Caco-2 cells as described above. As a control group, the bacteria were incubated under the same conditions without Caco-2 cells. After $2 \mathrm{~h}$ of incubation, the coculture cells were washed 3 times with PBS and harvested in Trizol reagent (Invitrogen, Carlsbad, CA) followed by RNA extraction immediately. The RNA was extracted from bacterial cells using the RNeasy Midi Kit (Tiangen, Beijing, China) according to the manufacturer's instructions. Complementary DNA was 
prepared with $1 \mu \mathrm{g}$ of total RNA as the template using the cDNA RT reagent kit (Takara, Kusatsu, Japan). The RNA and DNA concentrations were measured by an ND-1000 spectrophotometer (Thermo Fisher Scientific) at $260 / 280 \mathrm{~nm}$ and the quality was further assessed by agarose gel electrophoresis. The RT-qPCR was performed using SYBRGreen Premix Ex Taq (TaKaRa, Kusatsu, Japan) in a LightCycler instrument (Applied Biosystems, Waltham, MA) according to the manufacturer's protocol. The reaction mixture volume totaled $20 \mu \mathrm{L}$ containing $10 \mu \mathrm{L}$ of SYBR Green PCR Master Mix (TaKaRa), $0.4 \mu \mathrm{L}$ of ROX Reference Dye (TaKaRa), $1 \mu \mathrm{L}$ of $10 \mu M$ each primer, $2 \mu \mathrm{L}$ of cDNA, and $6.6 \mu \mathrm{L}$ of RNase-free water. The amplification conditions suggested by the manufacturer was $3 \mathrm{~min}$ of activation at $95^{\circ} \mathrm{C}$, followed by 40 cycles of denaturation at $95^{\circ} \mathrm{C}$ for $10 \mathrm{~s}$ and annealing at $60^{\circ} \mathrm{C}$ for $30 \mathrm{~s}$. Three independent repetitions were performed for the test and the $2^{-\Delta \Delta \mathrm{Ct}}$ method was used to calculate the relative expression levels of genes. The $16 \mathrm{~S}$ rRNA was amplified as an internal standard to normalize gene expression (Matsuki et al., 2004).

\section{Statistical Analysis}

Data are presented as the means \pm standard deviations of 3 independent experiments. Statistical significance was determined by Student's $t$-test or one-way ANOVA, and $P$-values $<0.05$ were considered significant.

\section{RESULTS}

\section{Growth of B. bifidum DNG6 Grown in Different Carbon Sources}

The growth curve is shown in Figure 1; the growth rates of $B$. bifidum DNG6 grown in different carbon sources were varied. When $B$. bifidum DNG6 was grown in $2^{\prime}$-FL, the lag phase $(12 \mathrm{~h})$ was significantly longer than that in glucose $(4 \mathrm{~h})$ and GOS $(6 \mathrm{~h} ; P<0.05)$. After reaching the stationary phase, the maximum optical density value (1.3) of $B$. bifidum DNG6 grown in 2 '-FL was significantly lower compared with that in glucose (1.7) and GOS $(1.5 ; P<0.05)$.

\section{Autoaggregation of B. bifidum DNG6 Grown in Different Carbon Sources}

Because autoaggregation has been demonstrated to be linked to bacteria adhesion (González-Rodríguez et al., 2012), we examined the aggregation of B. bifidum DNG6 grown in different carbon sources (Figure 2A).
Table 1. Primers used in reverse-transcription quantitative real-time PCR

\begin{tabular}{ll}
\hline Name & Sequence $^{1}\left(5^{\prime}-3^{\prime}\right)$ \\
\hline 16S rRNA & (F) AGAGTTTGATCCTGGCTCAG \\
& (R) TACGGTTACCTTGTTACGA \\
tal & (F) GCTCAAGGAACTCGGCAAGGTC \\
& (R) CGGAAGATGTCGGTGGCGTTG \\
eno & (F) TCCGCCTACATGCTCGACTACTAC \\
groL & (R) CTTCCCAGCCTTCCTCGTTGAAC \\
& (F) GCCAAGAAGGTCATCGTCTCCAAG \\
tuf & (F) GCAGCTTCTCACGGTCGTAATCG \\
& (R) GTCGGTGGTGGGGGACGAGGAGGAC
\end{tabular}

${ }^{1} \mathrm{~F}=$ forward; $\mathrm{R}=$ reverse.

Bifidobacterium bifidum DNG6 cultured in 2'-FL exhibited the highest percentage of autoaggregation $(34.32 \pm$ $2.53 \%)$, followed by that in GOS $(31.11 \pm 3.62 \%)$ and glucose $(29.63 \pm 1.79 \%)$, but no significant difference in autoaggregation was identified between the 3 groups $(P>0.05)$.

\section{Hydrophobicity of B. bifidum DNG6 Grown in Different Carbon Sources}

Hydrophobicity probably has a certain influence on nonspecific interactions of bacteria adhesion (Pan et al., 2006); the hydrophobicity of B. bifidum DNG6 grown in different carbon sources was studied (Figure

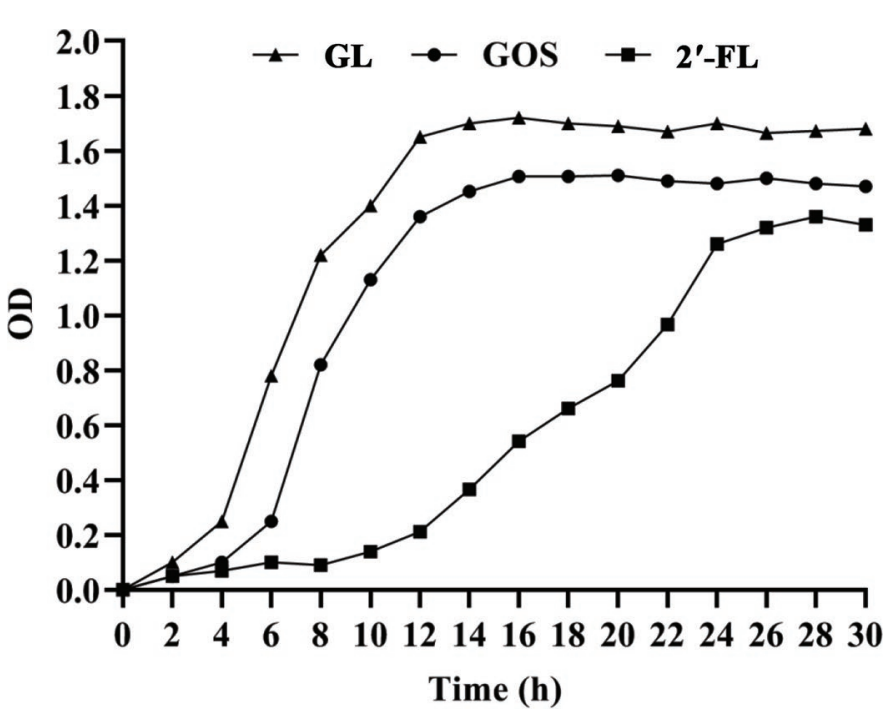

Figure 1. Growth curve of Bifidobacterium bifidum DNG6 grown in different carbon sources: glucose (GL), galactooligosaccharide (GOS), and 2 '-fucosyllactose (2'-FL), measured as the optical density (OD) at $600 \mathrm{~nm}$ in different culture times. The strain was controlled at $37^{\circ} \mathrm{C}$ in an anaerobic incubator. 
A

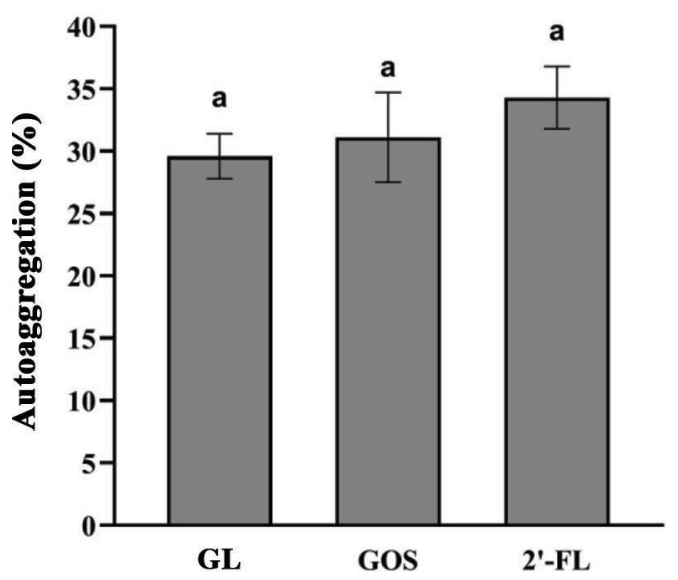

B

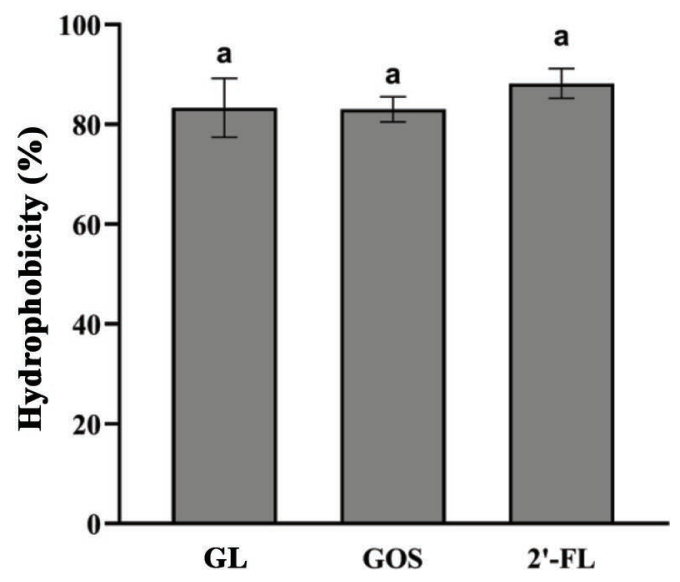

Figure 2. Cell surface properties of Bifidobacterium bifidum DNG6 grown in different carbon sources: glucose (GL), galactooligosaccharide (GOS), and 2'-fucosyllactose (2'-FL). Data are expressed as means \pm SD of 3 biological and technical replicates. Bars with different letters (a-c) differ significantly $(P<0.05)$. (A) Autoaggregation; (B) hydrophobicity.

2B). Bifidobacterium bifidum DNG6 cultured in 2'-FL exhibited the highest percentage of hydrophobicity $(88.24 \pm 3.02 \%)$, followed by that cultured in glucose $(83.27 \pm 5.47 \%)$ and GOS $(82.96 \pm 2.51 \%)$. Similar to autoaggregation results, the hydrophobicity values also did not differ significantly between the 3 groups $(P>$ $0.05)$.

\section{Adhesion of B. bifidum DNG6 Grown in Different Carbon Sources}

The Caco-2 cells are widely used as an important in vitro model for studying the interaction between bacteria and intestinal epithelial cells (Pinto et al., 1983). As shown in Figure 3, the adhesion of B. bifidum DNG6 grown in glucose was $7.08 \pm 0.27 \%$, whereas the adhesion of the reference strain $B$. animalis ssp. lactis BB12 grown in glucose was $6.53 \pm 0.34 \%(P>$ 0.05). The adhesion of B. bifidum DNG6 to Caco-2 cells ranged from $6.64 \pm 0.36 \%$ to $9.34 \pm 0.31 \%$ depending on the carbon sources. Bifidobacterium bifidum DNG6 grown in 2'-FL showed the highest adhesion rate (9.34 $\pm 0.31 \%)$ compared with that in GOS $(6.64 \pm 0.36 \%)$ and glucose $(7.08 \pm 0.27 \% ; P<0.01)$.

\section{Effect of Chemical Treatments on B. bifidum DNG6 Adhesion to Caco-2 Cells}

Different treatments were performed to determine the involvement of carbohydrates $\left(\mathrm{NaIO}_{4}\right)$, proteins (proteinase $\mathrm{K}$ and $\mathrm{LiCl}$ ), and teichoic acids $(\mathrm{PhOH})$ on the cell surface of B. bifidum DNG6 adhesion to Caco2 cells (Figure 4). All treatments inhibited the adhe- sion ability of $B$. bifidum DNG6 $(P<0.01)$. Among them, the adhesion rate of $B$. bifidum DNG6 was significantly decreased by $62.92 \%$ and $58.96 \%$ after $\mathrm{LiCl}$ and proteinase $\mathrm{K}$ treatment $(P<0.01)$, respectively, and the adhesion rate was decreased by $48.38 \%$ after $\mathrm{PhOH}$ treatment, whereas the adhesion of B. bifidum

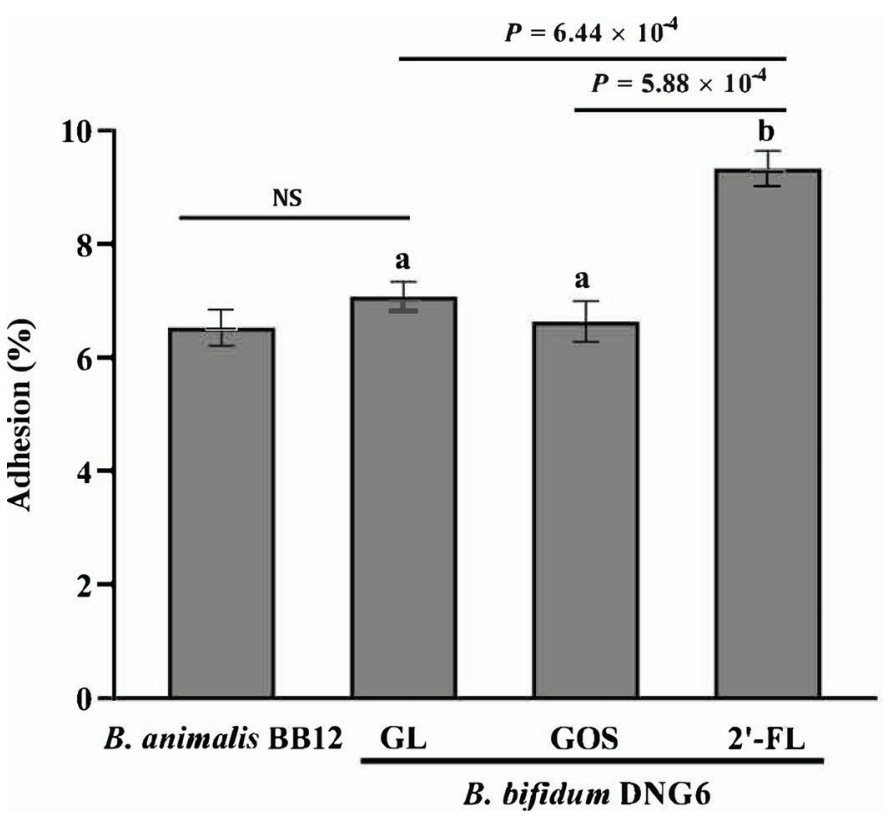

Figure 3. Adhesion of Bifidobacterium bifidum DNG6 to Caco-2 cells after culture with different carbon sources: glucose (GL), galactooligosaccharide (GOS), and 2'-fucosyllactose (2'-FL). Bifidobacterium animalis $\mathrm{BB} 12$ was used as the reference strain. Data are expressed as means \pm SD of 3 biological and technical replicates. Different letters $(\mathrm{a}, \mathrm{b})$ above bars indicate statistical differences $(P<0.01)$. 


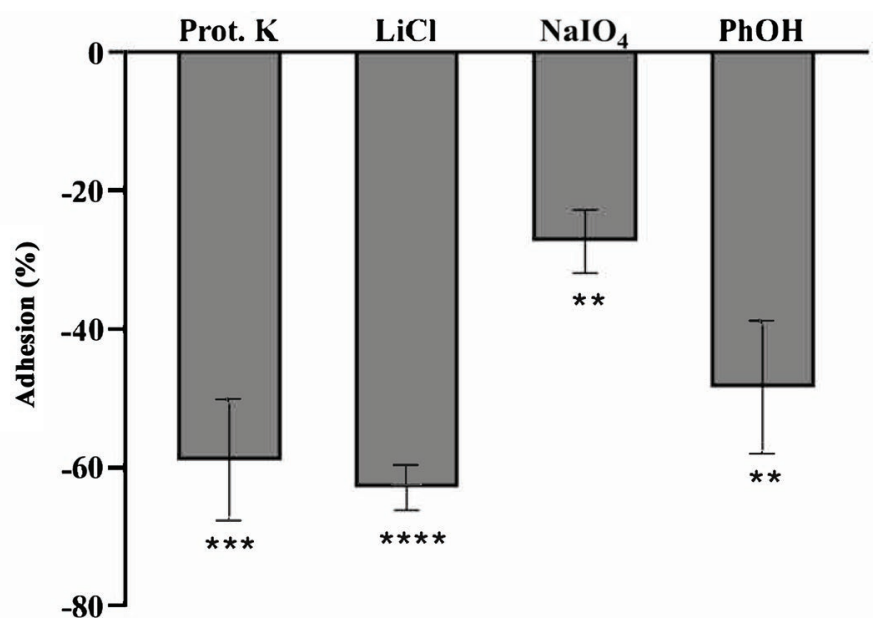

Figure 4. Percent changes in adhesion to Caco-2 cells of Bifidobacterium bifidum DNG6 after different chemical treatments. Data are presented as means $\pm \mathrm{SD}$ of 3 independent experiments. *indicates a statistically significant difference compared with the untreated bacteria ${ }^{* *} P<0.01 ;{ }^{* * *} P<0.001$; $\left.{ }^{* * * *} P<0.0001\right)$.

DNG6 was reduced by only $27.34 \%$ after treatment with $\mathrm{NaIO}_{4}$. At the same time, we observed the surface morphology of bacterial by TEM. The B. bifidum DNG6 showed a rough outer surface layer (Figure 5, arrowhead), whereas the surface protein of cell was removed and the cell surface became smooth after $\mathrm{LiCl}$ treatment; this result suggested that surface-exposed proteins in $B$. bifidum DNG6 were mainly involved in the adhesion process.

\section{Expression of Adhesion-Associated Genes in B. bifidum DNG6 in Response to Incubation with Caco-2 Cells}

To further analyze the effect of carbon source utilization on bacterial adhesion, we tested the expression levels of genes encoding Tal, Eno, GroEL, and EF-Tu. As shown in Figure 6, the expression levels of tested genes (tal, eno, groL, and tuf) were significantly increased in B. bifidum DNG6 cultivated with Caco-2 cells $(P<$ 0.01 ), indicating that these genes may be involved in the adhesion of bacteria to the host. However, these genes were expressed differently in B. bifidum DNG6 grown on different carbon sources. The expression of all genes was significantly higher in B. bifidum DNG6 grown in 2 -FL compared with that in glucose and GOS $(P<0.01)$. Among them, the highest expression levels (15.2-fold) were observed in tal, followed by eno (10.8-fold), tuf (9.2-fold), and groL (8.6-fold). These results suggest that 2 '-FL can promote the expression of adhesion-associated genes in B. bifidum DNG6 in response to contact with Caco-2 cells. Additionally, the expression of tal and tuf in B. bifidum DNG6 was significantly higher in GOS than in the glucose $(P<$ $0.01)$.

\section{DISCUSSION}

Adhesion to the intestinal mucosa plays a pivotal role in bifidobacteria colonization and modulation of the host immune system (Ventura et al., 2012). Evi-

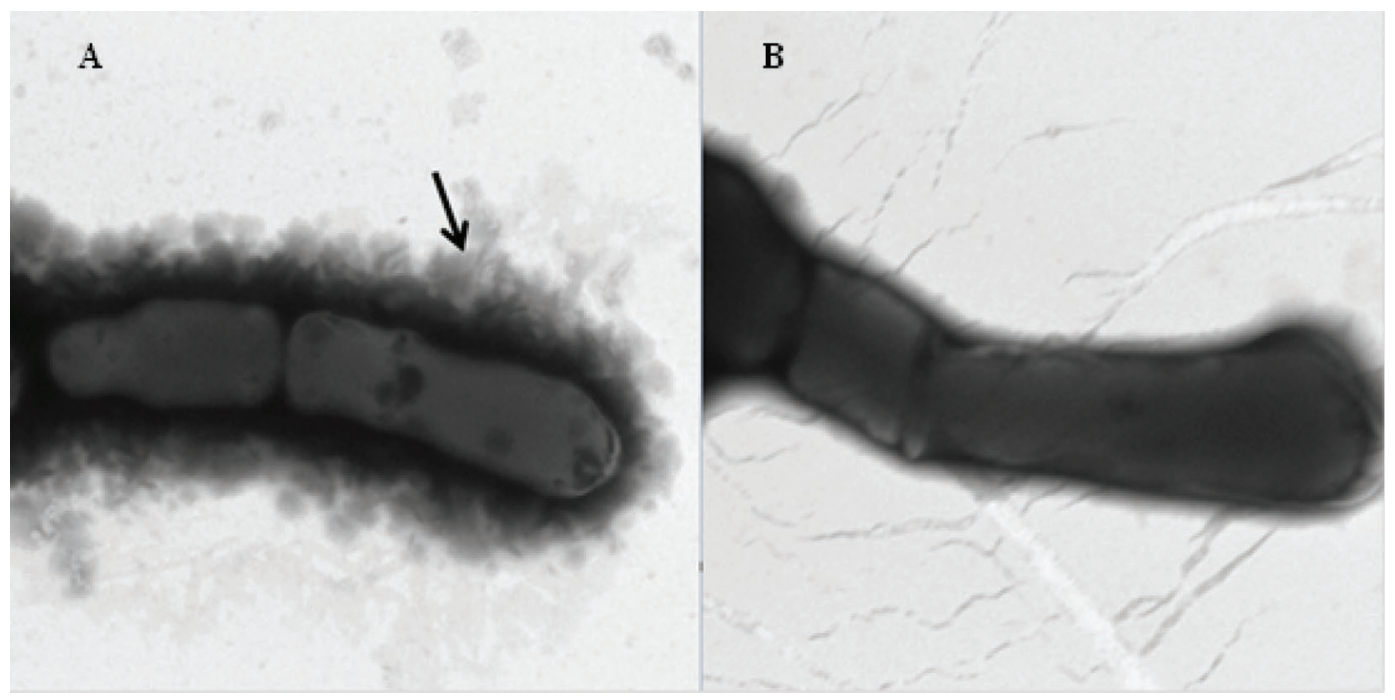

Figure 5. Transmission electron microscopy micrographs of Bifidobacterium bifidum DNG6. (A) Control, and (B) treatment with LiCl (magnification, $\times 60,000)$. Arrow indicates rough outer surface layer in control. 
dence suggests that the choice of carbon source affects the ability of bifidobacteria to adhere to and interact with epithelial cells (Riedel et al., 2006; Chichlowski et al., 2012). Many enzymes of carbon catabolism have been demonstrated that are cell wall associated and are involved in adhesion progress (Wei et al., 2014; Nishiyama et al., 2017). Thus, it is necessary to study the effect of carbon source utilization in the adhesion of bifidobacteria to intestinal epithelial cells.

The ability of bifidobacteria to use fucosyllactose varies among strains and species (Bunesova et al., 2016). Sakanaka et al. (2019) revealed an evolutionary adaptation of bifidobacteria to HMO structures; the fucosyllactose transporter-2 in B. longum ssp. infantis is a key factor for fucosyllactose utilization. Ruiz-Moyano et al. (2013) found that a specific GH29 fucosidase contributed to the ability of Bifidobacterium breve to use 2'-FL. In this study, we found that B. bifidum DNG6 could grow in medium containing 2 '-FL, indicating the strain has a specific enzyme system to hydrolyze fucosylated HMO. In addition, we observed that the growth rate of $B$. bifidum DNG6 cultured in 2'-FL was significantly lower compared with that in GOS, probably because the structure of $2^{\prime}-\mathrm{FL}$ is more complex than GOS and $2^{\prime}$-FL is decorated with a fucose residue attached to the lactose core, whereas GOS are short-chain linear polymers containing residues of galactose terminating with glucose, which requires more glycosidases and carbohydrate transporters to be used (Torres et al., 2010; Bode and Jantscher-Krenn, 2012).

Our results showed that the adhesion ability of $B$. bifidum DNG6 to Caco-2 cells changed according to the carbon source supplied in their growth medium. 2'-Fucosyllactose-grown B. bifidum DNG6 had significantly higher adhesion ability to Caco-2 cells compared with that grown in glucose and GOS. This result is similar to those of Wickramasinghe et al. (2015) who showed that growth of B. longum ssp. infantis on HMO also resulted in increased adherence to intestinal epithelial cells.

The cell envelope of bifidobacteria as the structural interface is critical for bacterial attachment and colonization because the surface-associated molecules directly affect host-microbe interactions (Desvaux et al., 2006; Nishiyama et al., 2017). In this study, the adhesion ability of B. bifidum DNG6 was significantly decreased after treatment with proteinase $\mathrm{K}$ and $\mathrm{LiCl}$, indicating that the surface-associated proteins of B. bifidum DNG6 play a key role in adhesion to Caco-2 cells. This result is consistent with Guglielmetti et al. (2008) who

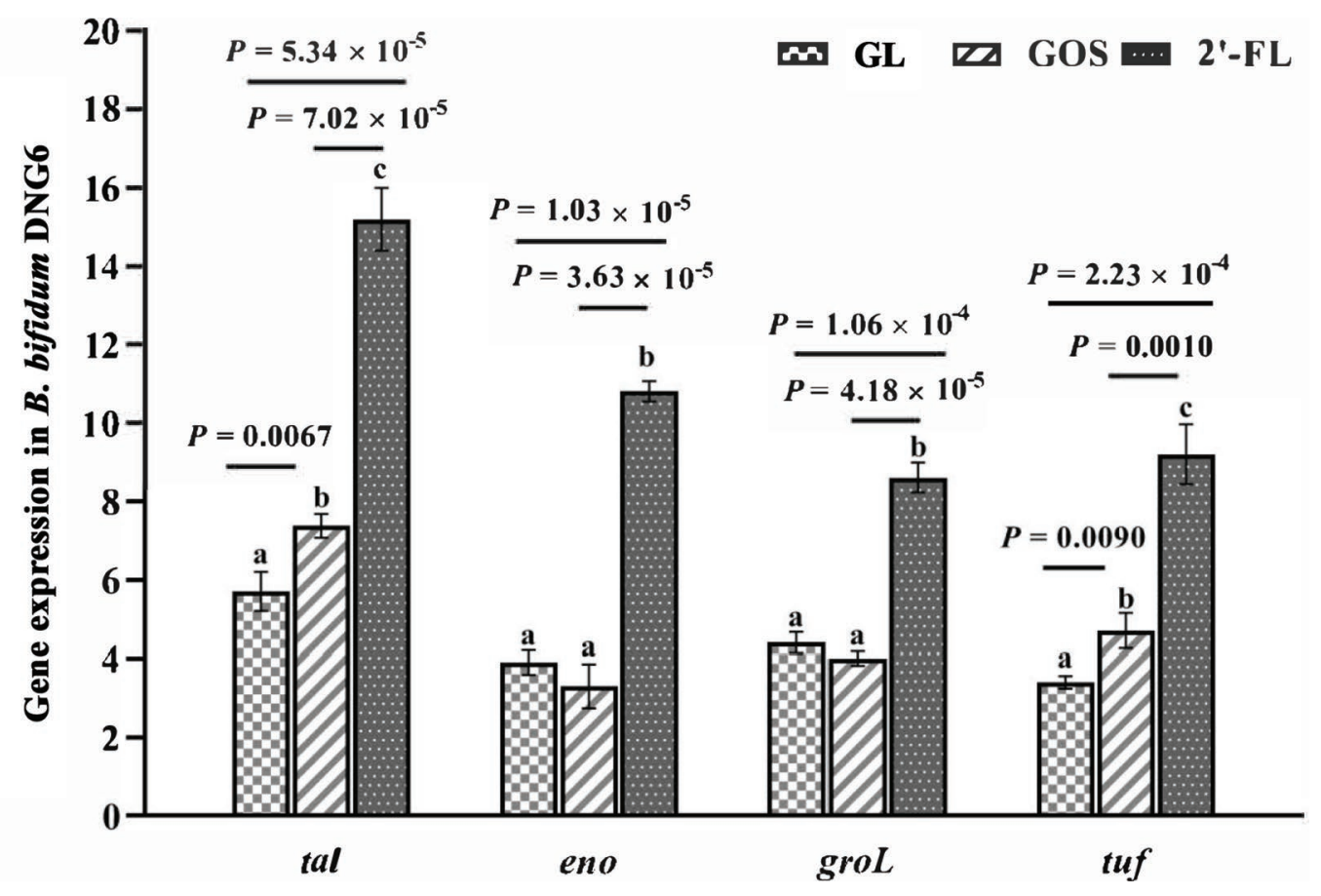

Figure 6. Relative expression of the adhesion-associated genes in Bifidobacterium bifidum DNG6 grown on different carbon sources in response to incubation with Caco-2 cells. As a control group, the strain was incubated under the same conditions without Caco-2 cells. The fold changes were calculated by dividing the gene expression values of the experimental group by that of the control group. Data are normalized against the internal reference gene of $16 \mathrm{~S}$ rRNA and expressed as means \pm SD of 3 biological replicates. Different letters (a-c) above bars indicate statistical significance $(P<0.01)$. GL = glucose; GOS = galactooligosaccharide; 2 '-FL $=2^{\prime}$-fucosyllactose. 
demonstrated that BopA, a surface protein, is directly involved in the adhesion of B. bifidum to Caco-2 cells, and the strain excited a strongly adhesive phenotype depending on the environmental conditions (the presence of sugars and $\mathrm{pH}$ ). In addition, we observed that $\mathrm{NaIO}_{4}$ and $\mathrm{PhOH}$ treatment inhibited the adhesion of B. bifidum DNG6, suggesting that carbohydrates and teichoic acids, in part, may also be involved in the adhesion of B. bifidum DNG6 to Caco-2 cells, which is in agreement with previous findings (Guglielmetti et al., 2009).

In this study, all the 4 tested genes (tal, eno, groL, and tuf) were expressed at higher levels in B. bifidum DNG6 following contact with Caco-2 cells. This agrees with the study by Wei et al. (2014), who concluded that these genes are involved in bifidobacterial adhesion. Furthermore, the expression of all genes was significantly higher in B. bifidum DNG6 grown in $2^{\prime}$-FL. These results suggest that 2 -FL may promote the interaction of bifidobacteria and intestinal epithelial cells by enhancing the expression of adhesion molecules.

Cell surface proteins have a great influence on the bifidobacterial adhesion through facilitating close contact with the gut epithelial cells (Desvaux et al., 2006). Acting as a cell surface receptor for human plasminogen, Eno plays a significant role in the interactions of bifidobacteria with the host (Candela et al., 2009). Tal, like other enzymes of the bifid shunt, has also been detected on the cell surface of several B. bifidum strains. González-Rodríguez et al. (2012) demonstrated that Tal can serve as an important adhesion factor favoring the colonization of $B$. bifidum in the intestinal tract.

The EF-Tu is a secondary protein, which in addition to the basic function in protein synthesis, also has the ability to bind plasminogen (Candela et al., 2007). Wei et al. (2014) indicated that EF-Tu as surface receptors for Bifidobacterium longum binding human plasminogen, is involved in bifidobacterial adhesion. Just like EF-Tu, GroEL is a kind of surface-associated proteins of bifidobacteria and contributed to its adhesion ability (Sun et al., 2016).

Our results demonstrated that 2'-FL can improve the adhesion ability of $B$. bifidum DNG6 in vitro. Laparra and Sanz (2009) reported that bacterial strains exhibit different adhesion ability in different in vitro models of intestinal epithelia, showing preferences for intestinal mucin. Therefore, further in vivo studies will be required to verify the in vitro results because in vitro models cannot fully mimic the mucosa-bacteria interactions, which is important for bacterial adhesion in vivo. Moreover, considering that the current results are based on the gene level, follow-up studies are needed at the protein level to elucidate specific surface proteins and their role in bifidobacteria adhesion to intestinal epithelial cells.

\section{CONCLUSIONS}

In this study, the growth and adhesion properties of B. bifidum DNG6 grown on different carbon sources differed. We show that 2'-FL improves the adhesion ability of B. bifidum DNG6 through high expression of adhesion-associated genes. These results provide more information about the involvement of 2'-FL as a carbon source in the adhesion of bifidobacteria. Our results suggest that the design of probiotic supplements may need to choose appropriate prebiotics, thereby effectively promoting the colonization of bifidobacteria.

\section{ACKNOWLEDGMENTS}

This study was supported by the National Key Research and Development Project of China (2018YFD0502404), Natural Science Foundation of Heilongjiang Province of China (grant no. C2018022), and Academic Backbone Plan of Northeast Agricultural University (grant no. 18XG27). The authors declare no conflicts of interest.

\section{REFERENCES}

Bianchi, M. A., D. Del Rio, N. Pellegrini, G. Sansebastiano, E. Neviani, and F. Brighenti. 2004. A fluorescence-based method for the detection of adhesive properties of lactic acid bacteria to Caco- 2 cells. Lett. Appl. Microbiol. 39:301-305. https://doi.org/10.1111/j .1472-765X.2004.01589.x.

Bode, L., and E. Jantscher-Krenn. 2012. Structure-function relationships of human milk oligosaccharides. Adv. Nutr. 3:383-391. https: //doi.org/10.3945/an.111.001404.

Bunesova, V., C. Lacroix, and C. Schwab. 2016. Fucosyllactose and Lfucose utilization of infant Bifidobacterium longum and Bifidobacterium kashiwanohense. BMC Microbiol. 16:248. https://doi.org/ 10.1186/s12866-016-0867-4.

Candela, M., S. Bergmann, M. Vici, B. Vitali, S. Turroni, B. J. Eikmanns, S. Hammerschmidt, and P. Brigidi. 2007. Binding of human plasminogen to Bifidobacterium. J. Bacteriol. 189:5929-5936. https://doi.org/10.1128/JB.00159-07.

Candela, M., E. Biagi, M. Centanni, S. Turroni, M. Vici, F. Musiani, B. Vitali, S. Bergmann, S. Hammerschmidt, and P. Brigidi. 2009. Bifidobacterial enolase, a cell surface receptor for human plasminogen involved in the interaction with the host. Microbiology 155:3294-3303. https://doi.org/10.1099/mic.0.028795-0.

Chichlowski, M., G. De Lartigue, J. B. German, H. E. Raybould, and D. A. Mills. 2012. Bifidobacteria isolated from infants and cultured on human milk oligosaccharides affect intestinal epithelial function. J. Pediatr. Gastroenterol. Nutr. 55:321-327. https://doi.org/ 10.1097/MPG.0b013e31824fb899.

Desvaux, M., E. Dumas, I. Chafsey, and M. Hebraud. 2006. Protein cell surface display in gram-positive bacteria: From single protein to macromolecular protein structure. FEMS Microbiol. Lett. 256:1-15. https://doi.org/10.1111/j.1574-6968.2006.00122.x.

Duranti, S., F. Turroni, G. A. Lugli, C. Milani, A. Viappiani, M. Mangifesta, L. Gioiosa, P. Palanza, D. van Sinderen, and M. Ventura. 2014. Genomic characterization and transcriptional studies of the 
starch-utilizing Bifidobacterium adolescentis 22L. Appl. Environ. Microbiol. 80:6080-6090. https://doi.org/10.1128/AEM.01993-14.

Gareau, M. G., P. M. Sherman, and W. A. Walker. 2010. Probiotics and the gut microbiota in intestinal health and disease. Nat. Rev. Gastroenterol. Hepatol. 7:503-514. https://doi.org/10.1038/ nrgastro.2010.117.

Gilad, O., B. Svensson, A. H. Viborg, B. Stuer-Lauridsen, and S. Jacobsen. 2011. The extracellular proteome of Bifidobacterium animalis ssp. lactis BB-12 reveals proteins with putative roles in probiotic effects. Proteomics 11:2503-2514. https://doi.org/10.1002/ pmic.201000716.

González-Rodríguez, I., B. Sánchez, L. Ruiz, F. Turroni, M. Ventura, P. Ruas-Madiedo, M. Gueimonde, and A. Margolles. 2012. Role of extracellular transaldolase from Bifidobacterium bifidum in mucin adhesion and aggregation. Appl. Environ. Microbiol. 78:39923998. https://doi.org/10.1128/AEM.08024-11.

Guglielmetti, S., I. Tamagnini, M. Minuzzo, S. Arioli, C. Parini, E. Comelli, and D. Mora. 2009. Study of the adhesion of Bifidobacterium bifidum MIMBb75 to human intestinal cell lines. Curr. Microbiol. 59:167-172. https://doi.org/10.1007/s00284-009-9415-x.

Guglielmetti, S., I. Tamagnini, D. Mora, M. Minuzzo, A. Scarafoni, S. Arioli, J. Hellman, M. Karp, and C. Parini. 2008. Implication of an outer surface lipoprotein in adhesion of Bifidobacterium bifidum to Caco-2 Cells. Appl. Environ. Microbiol. 74:4695-4702. https:// doi.org/10.1128/AEM.00124-08.

He, Y., S. Liu, D. E. Kling, S. Leone, N. T. Lawlor, Y. Huang, S. B. Feinberg, D. R. Hill, and D. S. Newburg. 2016. The human milk oligosaccharide 2-fucosyllactose modulates CD14 expression in human enterocytes, thereby attenuating LPS-induced inflammation. Gut 65:33-46. https://doi.org/10.1136/gutjnl-2014-307544.

Kavanaugh, D. W., J. O'Callaghan, L. F. Buttó, H. Slattery, J. Lane, M. Clyne, M. Kane, L. Joshi, and R. M. Hickey. 2013. Exposure of Bifidobacterium longum ssp. infantis to milk oligosaccharides increases adhesion to epithelial cells and induces a substantial transcriptional response. PLoS One 8:e67224. https://doi.org/10.1371/ journal.pone.0067224.

Laparra, J. M., and Y. Sanz. 2009. Comparison of in vitro models to study bacterial adhesion to the intestinal epithelium. Lett. Appl. Microbiol. 49:695-701. https://doi.org/10.1111/j.1472-765X.2009 .02729.x.

Liu, D., S. Wang, B. Xu, Y. Guo, J. Zhao, W. Liu, Z. Sun, C. Shao, X. Wei, Z. Jiang, X. Wang, F. Liu, J. Wang, L. Huang, D. Hu, X. He, C. U. Riedel, and J. Yuan. 2011. Proteomics analysis of Bifidobacterium longum $\mathrm{NCC} 2705$ growing on glucose, fructose, mannose, xylose, ribose, and galactose. Proteomics 11:2628-2638. https:// doi.org/10.1002/pmic.201100035.

Matsuki, T., K. Watanabe, J. Fujimoto, Y. Kado, T. Takada, K. Matsumoto, and R. Tanaka. 2004. Quantitative PCR with 16SrRNAgene-targeted species-specific primers for analysis of human intestinal bifidobacteria. Appl. Environ. Microbiol. 70:167-173. https:/ /doi.org/10.1128/AEM.70.1.167-173.2004.

Matsuki, T., K. Yahagi, H. Mori, H. Matsumoto, T. Hara, S. Tajima, E. Ogawa, H. Kodama, K. Yamamoto, T. Yamada, S. Matsumoto, and K. Kurokawa. 2016. A key genetic factor for fucosyllactose utilization affects infant gut microbiota development. Nat. Commun. 7:11939. https://doi.org/10.1038/ncomms11939.

Ninonuevo, M. R., Y. Park, H. Yin, J. Zhang, R. E. Ward, B. H. Clowers, J. B. German, S. L. Freeman, K. Killeen, R. Grimm, and C. B. Lebrilla. 2006. A strategy for annotating the human milk glycome. J. Agric. Food Chem. 54:7471-7480. https://doi.org/10 $.1021 /$ jf0615810.

Nishiyama, K., Y. Yamamoto, M. Sugiyama, T. Takaki, T. Urashima, S. Fukiya, A. Yokota, N. Okada, and T. Mukai. 2017. Bifidobacterium bifidum extracellular sialidase enhances adhesion to the mucosal surface and supports carbohydrate assimilation. MBio 8:e00928-17. https://doi.org/10.1128/mBio.00928-17.

Pan, W. H., P. L. Li, and Z. Liu. 2006. The correlation between surface hydrophobicity and adherence of Bifidobacterium strains from centenarians' faeces. Anaerobe 12:148-152. https://doi.org/10.1016/j anaerobe.2006.03.001.
Pinto, M., S. Robine Leon, and M. D. Appay. 1983. Enterocyte-like differentiation and polarization of the human colon carcinoma cell line Caco-2 in culture. Biol. Cell 47:323-330.

Riedel, C. U., F. Foata, D. R. Goldstein, S. Blum, and B. J. Eikmanns. 2006. Interaction of bifidobacteria with Caco-2 cells-adhesion and impact on expression profiles. Int. J. Food Microbiol. 110:62-68. https://doi.org/10.1016/j.ijfoodmicro.2006.01.040.

Roberfroid, M., and J. Slavin. 2000. Nondigestible oligosaccharides. Crit. Rev. Food Sci. Nutr. 40:461-480. https://doi.org/10.1080/ 10408690091189239.

Ruiz-Moyano, S., S. M. Totten, D. A. Garrido, J. T. Smilowitz, J. B. German, C. B. Lebrilla, and D. A. Mills. 2013. Variation in consumption of human milk oligosaccharides by infant gut-associated strains of Bifidobacterium breve. Appl. Environ. Microbiol. 79:6040-6049. https://doi.org/10.1128/AEM.01843-13.

Sakanaka, M., M. E. Hansen, A. Gotoh, T. Katoh, K. Yoshida, T. Odamaki, H. Yachi, Y. Sugiyama, S. Kurihara, J. Hirose, T. Urashima, J. Z. Xiao, M. Kitaoka, S. Fukiya, A. Yokota, L. Lo Leggio, M. Abou Hachem, and T. Katayama. 2019. Evolutionary adaptation in fucosyllactose uptake systems supports bifidobacteria-infant symbiosis. Sci. Adv. 5:eaaw7696. https://doi.org/10 $.1126 /$ sciadv.aaw7696.

Sivan, A., L. Corrales, N. Hubert, J. B. Williams, K. Aquino-Michaels, Z. M. Earley, F. W. Benyamin, Y. M. Lei, B. Jabri, M. L. Alegre, E. B. Chang, and T. F. Gajewski. 2015. Commensal Bifidobacterium promotes antitumor immunity and facilitates anti-PD-L1 efficacy. Science 350:1084-1089. https://doi.org/10.1126/science .aac4255.

Sun, Y., D. Q. Zhu, Q. X. Zhang, X. H. Pang, S. R. Sun, F. Liu, A. L. Li, and X. C. Meng. 2016. The expression of GroEL protein amplified from Bifidobacterium animalis subsp lactis KLDS 2.0603 and its role in competitive adhesion to Caco-2. Food Biotechnol. 30:292-305. https://doi.org/10.1080/08905436.2016.1244769.

Thomson, P., D. A. Medina, and D. Garrido. 2018. Human milk oligosaccharides and infant gut bifidobacteria: molecular strategies for their utilization. Food Microbiol. 75:37-46. https://doi.org/10 .1016/j.fm.2017.09.001.

Torres, D. P. M., M. P. F. Gonçalves, J. A. Teixeira, and L. R. Rodrigues. 2010. Galacto-oligosaccharides: Production, properties, applications, and significance as prebiotics. Compr. Rev. Food Sci Food Saf. 9:438-454. https://doi.org/10.1111/j.1541-4337.2010 .00119.x.

Turroni, F., F. Bottacini, E. Foroni, I. Mulder, J.-H. Kim, A. Zomer, B. Sanchez, A. Bidossi, A. Ferrarini, V. Giubellini, M. Delledonne, B. Henrissat, P. Coutinho, M. Oggioni, G. F. Fitzgerald, D. Mills, A. Margolles, D. Kelly, D. van Sinderen, and M. Ventura. 2010. Genome analysis of Bifidobacterium bifidum PRL2010 reveals metabolic pathways for host-derived glycan foraging. Proc. Natl. Acad. Sci. USA 107:19514-19519. https://doi.org/10.1073/ pnas.1011100107.

Turroni, F., C. Peano, D. A. Pass, E. Foroni, M. Severgnini, M. J. Claesson, C. Kerr, J. Hourihane, D. Murray, F. Fuligni, M. Gueimonde, A. Margolles, G. De Bellis, P. W. O'Toole, D. van Sinderen, J. R. Marchesi, and M. Ventura. 2012. Diversity of bifidobacteria within the infant gut microbiota. PLoS One 7:e36957. https://doi.org/10.1371/journal.pone.0036957.

Vandenplas, Y., I. Zakharova, and Y. Dmitrieva. 2015. Oligosaccharides in infant formula: More evidence to validate the role of prebiotics. Br. J. Nutr. 113:1339-1344. https://doi.org/10.1017/ S0007114515000823.

Vázquez, E., A. Barranco, M. Ramírez, A. Gruart, J. M. DelgadoGarcía, E. Martínez-Lara, S. Blanco, M. J. Martín, E. Castanys, R. Buck, P. Prieto, and R. Rueda. 2015. Effects of a human milk oligosaccharide, 2 '-fucosyllactose, on hippocampal long-term potentiation and learning capabilities in rodents. J. Nutr. Biochem. 26:455-465. https://doi.org/10.1016/j.jnutbio.2014.11.016.

Ventura, M., F. Turroni, M. O. C. Motherway, J. MacSharry, and D. van Sinderen. 2012. Host-microbe interactions that facilitate gut colonization by commensal bifidobacteria. Trends Microbiol. 20:467-476. https://doi.org/10.1016/j.tim.2012.07.002. 
Wei, X., S. Wang, X. Zhao, X. Wang, H. Li, W. Lin, J. Lu, D. Zhurina, B. Li, C. U. Riedel, Y. Sun, and J. Yuan. 2016. Proteomic profiling of Bifidobacterium bifidum S17 cultivated under in vitro conditions. Front. Microbiol. 7:97. https://doi.org/10.3389/fmicb 2016.00097.

Wei, X., X. Yan, X. Chen, Z. Yang, H. Li, D. Zou, X. He, S. Wang, Q. Cui, W. Liu, D. Zhurina, X. Wang, X. Zhao, L. Huang, M. Zeng, Q. Ye, C. U. Riedel, and J. Yuan. 2014. Proteomic analysis of the interaction of Bifidobacterium longum NCC2705 with the intestine cells Caco-2 and identification of plasminogen receptors. J. Proteomics 108:89-98. https://doi.org/10.1016/j.jprot.2014.04.038.

Westermann, C., M. Gleinser, S. C. Corr, and C. U. Riedel. 2016. A critical evaluation of bifidobacterial adhesion to the host tissue. Front. Microbiol. 7:1220. https://doi.org/10.3389/fmicb.2016 .01220 .

Wickramasinghe, S., A. R. Pacheco, D. G. Lemay, and D. A. Mills. 2015. Bifidobacteria grown on human milk oligosaccharides downregulate the expression of inflammation-related genes in Caco-2 cells. BMC Microbiol. 15:172. https://doi.org/10.1186/s12866-015 -0508-3.

Yassour, M., T. Vatanen, H. Siljander, A.-M. Hämäläinen, T. Härkönen, S. J. Ryhänen, E. A. Franzosa, H. Vlamakis, C. Hut- tenhower, D. Gevers, E. S. Lander, M. Knip, and R. J. Xavier. 2016. Natural history of the infant gut microbiome and impact of antibiotic treatment on bacterial strain diversity and stability. Sci. Transl. Med. 8:343ra81. https://doi.org/10.1126/scitranslmed .aad0917.

Zhu, D., Y. Sun, F. Liu, A. L. Li, L. Yang, and X. C. Meng. 2016. Identification of surface-associated proteins of Bifidobacterium animalis ssp. lactis KLDS 2.0603 by enzymatic shaving. J. Dairy Sci. 99:5155-5172. https://doi.org/10.3168/jds.2015-10581.

\section{ORCIDS}

Guofang Zhang (๑) https://orcid.org/0000-0002-4616-2721 Jingjing Zhao () https://orcid.org/0000-0003-3996-0546

Rong Wen @ https://orcid.org/0000-0002-1870-5223

Xumeng Zhu ๑ https://orcid.org/0000-0001-9491-963X

Libo Liu (1) https://orcid.org/0000-0002-6077-1988

Chun Li $\odot$ https://orcid.org/0000-0003-1603-7222 